\title{
Incidence of childhood fractures in affluent and deprived areas: population based study
}

\author{
Ronan A Lyons, Ann M Delahunty, Martin Heaven, Michael McCabe, Howard Allen, Pam Nash
}

Substantial evidence exists that poorer children in England, Scotland, and Wales and have considerably higher rates of deaths from injury than their more affluent counterparts. ${ }^{12}$ With the exception of specific groups, such as pedestrian injuries and poisoning, however, the socioeconomic profile on non-fatal injuries is less clear cut. $^{3}$ The English, Scottish, and Welsh health departments have set targets for a decrease in the assumed variation in incidence between affluent and deprived children in the absence of baseline data. In a population based incidence study we tested the hypothesis that fracture rates are similar among children from affluent and deprived areas.

\section{Methods and results}

Details of this study of new fractures among children in the Swansea and Neath Port Talbot area of south Wales during 1996 can be found in an earlier publication. ${ }^{4}$ We have previously shown that attendance in accident and emergency departments for fractures gives an unbiased estimate of incidence, unlike for other injuries, for which attendance decreases with increasing distance from a department. ${ }^{5}$

The area was divided into quarters of electoral wards $(n=82)$ on the basis of Townsend scores (means 6.3 (most deprived), 0.7, - 1.6, and -4.4 (least deprived) respectively); childhood populations were $12150,14018,19924$, and 22049 respectively. Analysis is based on 2399 children with one or more fractures in 1996. Crude and directly age and sex standardised rates were closely similar by quarter $(31.8 v 30.6,37.0 v 37.0,37.1 v 37.5,34.1 v$ 34.8 ). The $\chi^{2}$ test for trend was used to test for a relation between rate and quarter. The table gives crude fracture rates by quarter for all and specific causes. Fracture rates for all activities were similar across the quarters; affluent areas had higher rates of sports related fractures and poorer areas more assault related fractures.

\section{Comment}

The findings that fracture rates in children from affluent and deprived areas are similar is surprising and initially seems to be at odds with previous reports of higher injury mortality rates in poorer children. Mortality in childhood is heavily influenced by deaths from motor vehicle accidents. In 1996, 35\% of childhood deaths from injuries and poisoning in England and Wales were due to motor vehicle accidents, compared with a figure of $1.4 \%$ of fractures in this study. A further $29 \%$ of childhood deaths were due to poisoning, fires, and drowning; only $4 \%$ of fatal childhood injuries were due to falls. Thus, factors resulting in fatal childhood injuries differ from those resulting in

\begin{tabular}{|c|c|c|c|c|c|}
\hline \multicolumn{6}{|c|}{ Number of fractures per 1000 children (total number) by deprivation quarter } \\
\hline \multirow[b]{2}{*}{ Activity } & \multicolumn{4}{|c|}{ Deprivation quarter } & \multirow[b]{2}{*}{$\begin{array}{l}P \text { value for } \\
\text { trend }\end{array}$} \\
\hline & Highest & $\begin{array}{l}\text { Second } \\
\text { highest }\end{array}$ & $\begin{array}{l}\text { Second } \\
\text { lowest }\end{array}$ & Lowest & \\
\hline All activities & $34.1(752)$ & $37.1(740)$ & $37.2(521)$ & $31.8(386)$ & 0.52 \\
\hline All sports & $11.1(245)$ & $12.9(258)$ & $13.3(187)$ & $14.4(175)$ & 0.007 \\
\hline Organised sports & $4.2(92)$ & $5.4(107)$ & $5.5(77)$ & $5.6(68)$ & 0.06 \\
\hline Soccer & $2.7(60)$ & $2.4(47)$ & $2.9(40)$ & $3.7(45)$ & 0.11 \\
\hline Rugby & $1.5(32)$ & $2.4(47)$ & $1.5(21)$ & $2.2(27)$ & 0.30 \\
\hline Roller sports & $1.3(28)$ & $1.5(29)$ & $2.0(28)$ & $2.0(24)$ & 0.05 \\
\hline Cycling & $2.9(63)$ & $2.2(43)$ & $3.1(44)$ & $3.0(36)$ & 0.57 \\
\hline Gymnastics & $0.6(13)$ & $0.5(10)$ & $0.8(11)$ & $0.5(6)$ & 0.95 \\
\hline Combat sports & $0.4(9)$ & $0.7(14)$ & $0.4(5)$ & $0.2(2)$ & 0.23 \\
\hline Horseriding & $0.1(1)$ & $0.6(11)$ & $0.4(6)$ & $0.5(6)$ & 0.04 \\
\hline Road traffic related & $0.5(10)$ & $0.7(13)$ & $0.6(8)$ & $0.2(3)$ & 0.51 \\
\hline Assault related & $1.5(32)$ & $1.7(33)$ & $0.9(13)$ & $0.6(7)$ & 0.01 \\
\hline
\end{tabular}

fractures. Similarities in fracture rates across areas could be due to differential risk exposures-for example, less time spent on a particular activity in a more dangerous environment could balance fracture rates. We are currently testing this hypothesis in a different study.

This is an ecological study showing that the fracture rate in more deprived areas (not necessarily in individuals) is similar to that in affluent areas. Many interventions focusing on reducing injuries in deprived children, however, target areas or schools rather than individuals, and for these the relation between injury rate and area deprivation score is more important than that at individual level.

Despite the results of this study it is still reasonable to target injury prevention initiatives in more deprived areas as these children experience a variety of other disadvantages. Interventions to reduce injuries related to violence in children from deprived areas and those targeting road traffic accidents and poisoning would be particularly welcome.

Contributors: RAL and AMD were the lead investigators and wrote the paper. RAL and MH carried out the statistical analysis. MMcC, HA, and PN contributed to the study design, organised data collection in the hospitals, and commented on drafts of the paper. RAL will act as guarantor for the paper.

Funding: None.

Competing interests: None declared.

1 Report of the Working Group on Inequalities in Health. London: HMSO, 1980. (Black report.)

2 Morrison A, Stone DH, Redpath A, Campbell H. Trends in socioeconomic differentials in childhood injury mortality in Scotland 1981-95. BMJ 1999;318:567-8.

3 Williams JM, Currie CE, Wright P, Elton RA, Beattie TF. Socio-economic status and adolescent injuries. Soc Sci Med 1997;44:1881-91.

4 Lyons RA, Delahunty AM, Kraus D, Heaven M, McCabe M, Allen H, et al. Children's fractures: a population based study. Injury Prevention 1999;5:129-32.

5 Lyons RA, Lo SV, Heaven M, Littlepage BNC. Injury surveillance in children-usefulness of a centralised database of accident and emergency attendances. Injury Prevention 1995;1:173-6.

(Accepted 5 November 1999)
Welsh Combined Centres for Public Health, University of Wales College of Medicine, Swansea SA1 1LT Ronan A Lyons senior lecturer

Department of Public Health, Iechyd Morgannwg Health, Swansea SA1 1LT

Ann M Delahunty primary care adviser Martin Heaven information scientist

Accident and Emergency Department, Morriston Hospital, Swansea SA6 6NL

Michael McCabe consultant in accident and emergency medicine

Howard Allen comsultant in accident and emergency medicine

Local Accident Centre, Neath General Hospital, Neath SA11 2LQ

Pam Nash consultant in accident and emergency medicine

Correspondence to: R A Lyons ronan.lyons@ wales.nhs.uk morgannwg-ha.

BMJ 2000;320:149 